\title{
Crenarchaeol dominates the membrane lipids of Candidatus Nitrososphaera gargensis, a thermophilic Group I.1b Archaeon
}

\author{
Angela Pitcher ${ }^{1}$, Nicolas Rychlik ${ }^{2}$, Ellen C Hopmans ${ }^{1}$, Eva Spieck ${ }^{2}$, W Irene C Rijpstra ${ }^{1}$, \\ Jort Ossebaar ${ }^{1}$, Stefan Schouten ${ }^{1}$, Michael Wagner ${ }^{3}$ and Jaap S Sinninghe Damsté ${ }^{1}$ \\ ${ }^{1}$ Department of Marine Organic Biogeochemistry, NIOZ Royal Netherlands Institute for Sea Research, \\ Den Burg, The Netherlands; ${ }^{2}$ Biocenter Klein Flottbek, Microbiology $\&$ Biotechnology, University of Hamburg, \\ Hamburg, Germany and ${ }^{3}$ Department of Microbial Ecology, University of Vienna, Wien, Austria
}

\begin{abstract}
Analyses of archaeal membrane lipids are increasingly being included in ecological studies as a comparatively unbiased complement to gene-based microbiological approaches. For example, crenarchaeol, a glycerol dialkyl glycerol tetraether (GDGT) with a unique cyclohexane moiety, has been postulated as biomarker for ammonia-oxidizing Archaea (AOA). Crenarchaeol has been detected in Nitrosopumilus maritimus and 'Candidatus Nitrosocaldus yellowstonii' representing two of the three lineages within the Crenarchaeota containing described AOA. In this paper we present the membrane GDGT composition of 'Candidatus Nitrososphaera gargensis', a moderately thermophilic AOA, and the only cultivated Group I.1b Crenarchaeon. At a cultivation temperature of $46 \mathrm{C}$, GDGTs of this organism consisted primarily of crenarchaeol, its regioisomer, and a novel GDGT. Intriguingly, 'Ca. N. gargensis' is the first cultivated archaeon to synthesize substantial amounts of the crenarchaeol regioisomer, a compound found in large relative abundances in tropical ocean water and some soils, and an important component of the TEX . $_{86}$ paleothermometer. Intact polar lipid (IPL) analysis revealed that ' $\mathrm{Ca}$. N. gargensis' synthesizes IPLs similar to those reported for the Goup I.1a AOA, Nitrosopumilus maritimus SCMI, in addition to IPLs containing uncharacterized headgroups. Overall, the unique GDGT composition of ' $\mathrm{Ca}$. $\mathrm{N}$. gargensis' extends the known taxonomic distribution of crenarchaeol synthesis to the Group I.1b Crenarchaeota, implicating this clade as a potentially important source of crenarchaeol in soils and moderately high temperature environments. Moreover, this work supports the hypothesis that crenarchaeol is specific to all AOA and highlights specific lipids, which may prove useful as biomarkers for 'Ca. N. gargensis'-like AOA.

The ISME Journal (2010) 4, 542-552; doi:10.1038/ismej.2009.138; published online 24 December 2009

Subject Category: Geomicrobiology and microbial contributions to geochemical cycles

Keywords: crenarchaeol; intact polar lipids; 'Ca. Nitrososphaera gargensis'; ammonia oxidation; Crenarchaeota
\end{abstract}

\section{Introduction}

The importance of Group I Crenarchaeota (that is, those not belonging to the well-known class of Thermoprotei) in the biogeochemical cycling of nitrogen and carbon is becoming increasingly evident, as culture-independent studies reveal the ubiquity and potential activity of these organisms in nature (for example, Francis et al., 2007; Beman et al., 2008; Prosser and Nicol, 2008 and references therein). Environmental analyses demonstrating the presence of abundant and diverse putative Group I

Correspondence: A Pitcher, Department of Marine Organic Biogeochemistry, NIOZ Royal Netherlands Institute for Sea Research, P.O. Box 59, Den Burg (Texel) 1790 AB, The Netherlands. E-mail: apitcher@nioz.nl

Received 25 August 2009; revised 10 November 2009; accepted 16 November 2009; published online 24 December 2009
Crenarchaeota-associated genes coding for $16 \mathrm{~S}$ rRNA and the $\alpha$ subunit of ammonia monooxygenase $(a m o A)$ in the marine water column (Francis et al., 2005), estuarine sediments (Beman and Francis, 2006), sponges (Steger et al., 2008), soils (Leininger et al., 2006) and hot springs (Zhang et al., 2008), indicate that these prevalent Archaea are also predominantly ammonia oxidizers. Archaeal amo $A$ copy numbers often exceed those of bacteria, thus suggesting that Archaea may even dominate bacteria in ammonia oxidation under certain conditions (for example, Leininger et al., 2006; Wuchter et al., 2006; Mincer et al., 2007; Martens-Habbena et al., 2009). Despite their apparent ubiquity and potential ecological importance, culturing efforts in concert with these discoveries have resulted in the enrichment and characterization of only a few ammonia-oxidizing Archaea (AOA) to date, together representing three phylogenetic lineages (Könneke et al., 2005; 
de la Torre et al., 2008; Hatzenpichler et al., 2008). The recent enrichment of 'Candidatus Nitrososphaera gargensis' (Hatzenpichler et al., 2008) has demonstrated the capacity for ammonia oxidation by moderately thermophilic Archaea and extended this capability to the Group I.1b Crenarchaeota, a clade comprised predominantly of 16S rRNA gene sequences recovered from soils.

The core (that is, apolar) component of crenarchaeal cellular membrane lipids, in general, is dominated by glycerol dialkyl glycerol tetraethers (GDGTs) (for example, Figure 1), which may contain multiple cyclopentane moieties (see overviews in Macalady et al., 2004; Schouten et al., 2007c). For a time, a unique GDGT, crenarchaeol, which contains a cyclohexane moiety in addition to its four cyclopentane moieties (Figure 1), was observed in natural samples but not in crenarchaeal cultures until its formal characterization from GDGTs extracted from a co-culture of Cenarchaeum symbiosum and the marine sponge Axinella mexicana (Sinninghe Damsté et al., 2002). Consequently, it was proposed that the crenarchaeol found so ubiquitously in nature originated from mesophilic Crenarchaeota, a hypothesis supported by confirmation of crenarchaeol synthesis by the marine Group I.1a Crenarchaeon, Nitrosopumilus maritimus SCM1 (Schouten et al., 2008).

Since then, however, crenarchaeol recovery from hot springs (Pearson et al., 2004; Zhang et al., 2006; Pitcher et al., 2009) and confirmation of crenarchaeol synthesis by the ammonia-oxidizing thermophile (growth temperature of $72^{\circ} \mathrm{C}$ ), ' $\mathrm{Ca}$. N. yellowstonii' (ThAOA/HWCG III) (de la Torre et al., 2008), has shown that crenarchaeol is also synthesized by non-mesophilic Crenarchaeota, effectively negating the original hypothesis. Instead, a number of studies have linked the presence of putative AOA to the occurrence of crenarchaeol (Wuchter et al., 2004; Coolen et al., 2007; Schouten et al., 2007a). The significant correlation between GDGT concentrations (including crenarchaeol) and Crenarchaeota Group I.1b amoA copy numbers in soil, further indicated that Group I.1b AOA specifically may also synthesize crenarchaeol (Leininger et al., 2006). Taken together, these findings suggest that crenarchaeol is a specific biomarker for AOA (de la Torre et al., 2008).

In addition to crenarchaeol, the regioisomer of crenarchaeol (cf. Sinninghe Damsté et al., 2002) is also abundant in certain settings, particularly in tropical marine environments (Schouten et al., 2002; Kim et al., 2008). However, none of the previously enriched or isolated Crenarchaea produce substantial amounts of the crenarchaeol regioisomer, despite producing crenarchaeol (Sinninghe Damsté et al., 2002; Wuchter et al., 2005; Schouten et al., 2007a, 2008; de la Torre et al., 2008). This discrepancy is also important to investigate as the regioisomer of crenarchaeol is used, together with several other GDGTs, in the $\mathrm{TEX}_{86}$ paleothermometer (Schouten et al., 2002) (Figure 1). The TEX ${ }_{86}$ has been shown to correlate well with in situ temperatures in sea water enrichment cultures
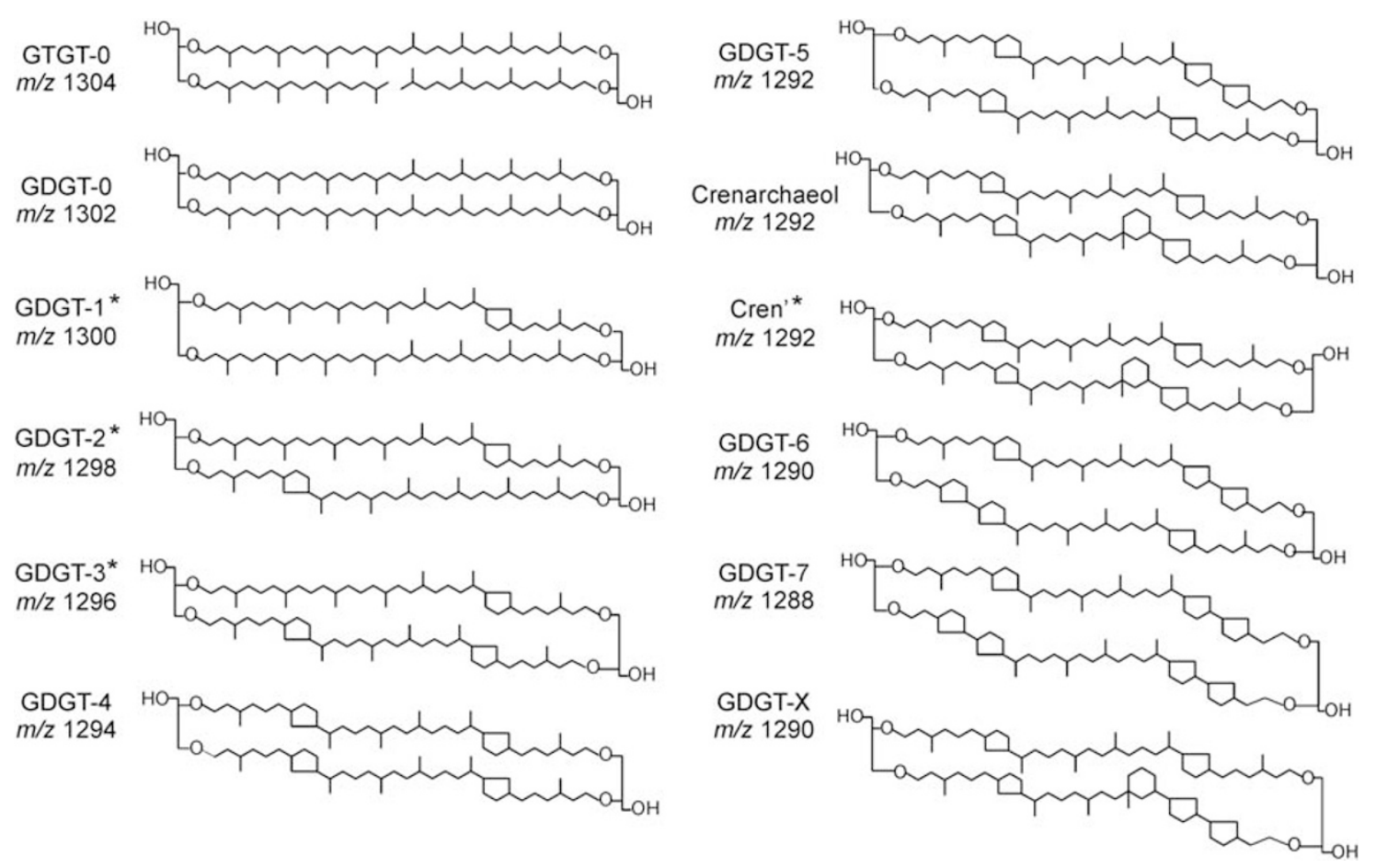

Figure 1 Structures analyzed in this study: glycerol trialkyl tetraether (GTGT)-0, glycerol dialkyl glycerol tetraethers (GDGTs) 0-7 including crenarchaeol, the crenarchaeol regioisomer $\left(\mathrm{cren}^{\prime}\right)$ and the new GDGT-X. GDGTs used to calculate the TEX ${ }_{86}$ ratio are indicated by stars. 
(Wuchter et al., 2004; Schouten et al., 2007a), as well as the marine water column (Wuchter et al., 2005). However, a calibration of the $\mathrm{TEX}_{86}$ by cultivation efforts has not been possible because of the near-lack of the regioisomer in cultures compared with relative abundances observed in natural environments at similar temperatures (cf. Schouten et al., 2007a). Through analysis of the core GDGT and intact polar lipid (IPL)-GDGT composition of 'Ca. N. gargensis', we have been able to further investigate the phylogenetic distribution of crenarchaeol and its regioisomer in AOA. In addition, we have analyzed lipids of ' $\mathrm{Ca}$. N. gargensis' cultivated at three growth temperatures to determine whether slight temperature differences result in the modification of its GDGT distribution.

\section{Materials and methods}

\section{Culture conditions}

The ammonia-oxidizing enrichment culture of 'Candidatus N. gargensis' (Hatzenpichler et al., 2008) was grown in mineral medium modified from Krümmel and Harms (1982) containing $\mathrm{KH}_{2} \mathrm{PO}_{4}(0.4 \mathrm{mM}), \mathrm{KCl}$ (1 mM), $\mathrm{MgSO}_{4}(0.2 \mathrm{mM}), \mathrm{CaCl}_{2}(1 \mathrm{mM})$ and $\mathrm{NaCl}$ $(10 \mathrm{mM})$. In all, $1 \mathrm{ml}$ trace element solution (Ehrich et al., 1995) and a small amount of cresol red were added to the final medium. In contrast to the previous protocol (Hatzenpichler et al., 2008), the substrate concentration was reduced to $0.5 \mathrm{mM}$ $\mathrm{NH}_{4} \mathrm{Cl}$ from $2.0 \mathrm{mM}$. A total of $4.5 \mathrm{l}$ of medium was prepared in 5-l bottles and inoculated with $50 \mathrm{ml}$ of an active preculture. Incubation was carried out in the dark at $46{ }^{\circ} \mathrm{C}$ for 3 weeks with moderate stirring (150 r.p.m.). The pH was adjusted to 7.8 and kept constant by daily titration using $15 \%(\mathrm{w} / \mathrm{v}) \mathrm{NaHCO}_{3}$. The consumption of ammonia was regularly measured by test sticks (Merck, Darmstadt, Germany) followed by replenishing the substrate with a $5 \mathrm{mM}$ sterile stock solution. In total, $3-4 \mathrm{mM} \mathrm{NH}_{4} \mathrm{Cl}$ were oxidized before cells were harvested by centrifugation $(14000 \mathrm{~g})$ and washed in $0.9 \% \mathrm{NaCl}$. Several 5-l bottles were collected, and the pellet was stored at $-20^{\circ} \mathrm{C}$ until final analysis. In the enrichments used in this study, a single archaeal operational taxonomic unit was present, which showed 98-99\% 16S RNA gene sequence similarity to ' $C a$. N. gargensis' (Hatzenpichler et al., 2008). In addition, the enrichment also contained a $\beta$-proteobacterium and possibly several other bacteria (Hatzenpichler et al., 2008). Cells for the temperature experiment were grown in 3-l flasks with $1.5 \mathrm{l}$ medium without stirring.

\section{Core lipid analysis}

Acid hydrolysis was carried out on freeze-dried biomass of cultivated ' $\mathrm{Ca}$. N. gargensis' to cleave polar headgroups. Biomass was refluxed in $2 \mathrm{ml}$ of $5 \% \mathrm{HCl}$ in methanol $(\mathrm{MeOH})$ for $3 \mathrm{~h}$. The cooled solution was adjusted to $\mathrm{pH} 5$ with $2 \mathrm{~N} \mathrm{KOH:MeOH}$ $(1: 1 \mathrm{v} / \mathrm{v})$. Bidistilled water was added to a final ratio of $\mathrm{H}_{2} \mathrm{O}: \mathrm{MeOH}(1: 1 \mathrm{v} / \mathrm{v})$ and this mixture was washed three times with dichloromethane (DCM). The DCM fractions were collected and dried over $\mathrm{Na}_{2} \mathrm{SO}_{4}$. The extract was dissolved in hexane:propanol $(99: 1 \mathrm{v} / \mathrm{v})$ filtered over a $0.4 \mu \mathrm{m}$ PTFE filter before analysis by high-performance liquid chromatography (HPLC) atmospheric pressure chemical ionization mass spectrometry (HPLC-Atmospheric Pressure Chemical Ionization (APCI)/mass spectrometry (MS)).

\section{HPLC-APCI/MS analysis}

Archaeal GDGTs were analyzed using a modified procedure from Hopmans et al. (2000) and Schouten et al. (2007b). Archaeal GDGTs were detected with full scan analysis from $\mathrm{m} / \mathrm{z} \quad 900-1400$ and the relative abundance determined by integration of the peak areas of their $[\mathrm{M}+\mathrm{H}]^{+}$and $[\mathrm{M}+\mathrm{H}+1]^{+}$ions.

\section{Identification of a novel GDGT- ' $X$ '}

Individual GDGTs of ' $\mathrm{Ca}$. N. gargensis' were isolated by semi-preparative HPLC according to the procedure described by Smittenberg et al. (2002). The fraction enriched in GDGT-X was subjected to ether bond cleavage as described by Hoefs et al. (1997) and analyzed by gas chromatography/mass spectrometry (GC/MS) for biphytanes. GC/MS analysis was carried out on a Thermofinnigan TRACE GC equipped with a fused silica capillary column $(25 \mathrm{~m} \times 0.32 \mathrm{~mm})$ coated with CP Sil-5 (film thickness $0.12 \mu \mathrm{m}$ ) and helium as the carrier gas. Sample was dissolved in hexane and injected at $70^{\circ} \mathrm{C}$. Subsequently the oven was programmed to increase to $130{ }^{\circ} \mathrm{C}$ at $20^{\circ} \mathrm{Cmin}^{-1}$ and then to $320^{\circ} \mathrm{C}$ at $4^{\circ} \mathrm{Cmin}^{-1}$, where it was held for $10 \mathrm{~min}$. The GC was coupled with a Thermofinnigan DSQ quadrupole MS with an ionization energy of $70 \mathrm{eV}$ scanning a mass range of $\mathrm{m} / \mathrm{z} \quad 50-800$ at three scans per second.

\section{IPL analysis}

Intact polar lipids were extracted from freeze-dried biomass using a modified Bligh and Dyer technique (Bligh and Dyer, 1959). A known volume of singlephase solvent mixture of MeOH:DCM:phosphate buffer $(2: 1: 0.8 \mathrm{v} / \mathrm{v} / \mathrm{v})$ was added to the sample in a centrifuge tube and placed in an ultrasonic bath for $10 \mathrm{~min}$. The extract and residue were separated by centrifuging at 2500 r.p.m. for $5 \mathrm{~min}$ and the solvent mixture collected in a separate flask (three times). The DCM and phosphate buffer were added to the single-phase extract to give a new ratio of MeOH:DCM:phosphate buffer (1:1:0.9 v/v/v) and to induce phase separation. The extract was centrifuged at 2500 r.p.m. for $5 \mathrm{~min}$. DCM phase was collected in a round-bottom flask and the methanol:phosphate buffer phase was washed two 
additional times with DCM. The combined DCM phases were reduced under rotary vacuum and evaporated to dryness under a stream of $\mathrm{N}_{2}$. Residual biomass was re-extracted using 5\% trichloroacetic acid instead of phosphate buffer according to Sturt et al. (2004), and analyzed separately. This extract contained the same IPLs identified in the first extraction, but in much lesser amounts.

\section{HPLC-electrospray ionization (ESI)/MS}

Intact polar lipid-glycerol dialkyl glycerol tetraethers were analyzed according to conditions described previously (Schouten et al., 2008) as modified from Sturt et al. (2004). For the analysis an Agilent (Palo-Alto, CA, US) 1100 series LC equipped with a thermostatted auto-injector was coupled to a Thermo TSQ Quantum EM triple quadrupole MS equipped with an Ion Max source with ESI probe. Detection was achieved using positive ion ESI/MS by scanning mass range $\mathrm{m} / \mathrm{z}$ 1000-2000.

\section{Results}

Core lipids

High-performance liquid chromatography-APCI/ mass spectrometry analysis of the GDGTs released from acid-hydrolyzed whole-cell biomass from 'Ca. N. gargensis', grown at its optimal growth temperature of $46^{\circ} \mathrm{C}$, revealed that it produces predominantly crenarchaeol and the crenarchaeol regioisomer (Figure 2b). GDGTs 0-4 were also present, but in very low abundances relative to crenarchaeol and its regioisomer (Table 1). In addition, a GDGT with a $[\mathrm{M}+\mathrm{H}]^{+}$of $\mathrm{m} / \mathrm{z} 1290$ (that is, six rings or double bonds) was present, which eluted earlier than GDGT-6 known to occur in (hyper)thermophilic Archaea, suggesting that it represented a novel core membrane lipid (henceforth referred to as 'GDGT-X').

Tentative identification of GDGT-X was carried after isolation with semi-preparative HPLC and treatment with $\mathrm{HI} / \mathrm{LiAlH}_{4}$ to release the carbon skeletons of the GDGT. GC/MS analysis revealed the presence of two $\mathrm{C}_{40}$ isoprenoidal hydrocarbons present in approximately equal abundance, indicating that together they comprised the intact GDGT-X. The first eluting isoprenoid had an MS and retention time identical to that of a biphytane with two cyclopentane moieties (de Rosa and Gambacorta, 1988; Hoefs et al., 1997; Schouten et al., 1998), with characteristic fragment ions at $\mathrm{m} / \mathrm{z} 97,125,165$ and 194, and an $\mathrm{M}^{+}$ion of $\mathrm{m} / \mathrm{z} 558$ (Figure 3a). The second eluting compound had a mass spectrum with fragment ions at $\mathrm{m} / \mathrm{z} 95,151,163$ and 261 , and a fragment of $\mathrm{m} / \mathrm{z} 539$, likely corresponding to an $\mathrm{M}^{+}-15$ ion (Figure $3 \mathrm{~b}$ ). The latter would be in agreement with a biphytane carbon skeleton containing four cyclic moieties; the mass spectrum of this com-

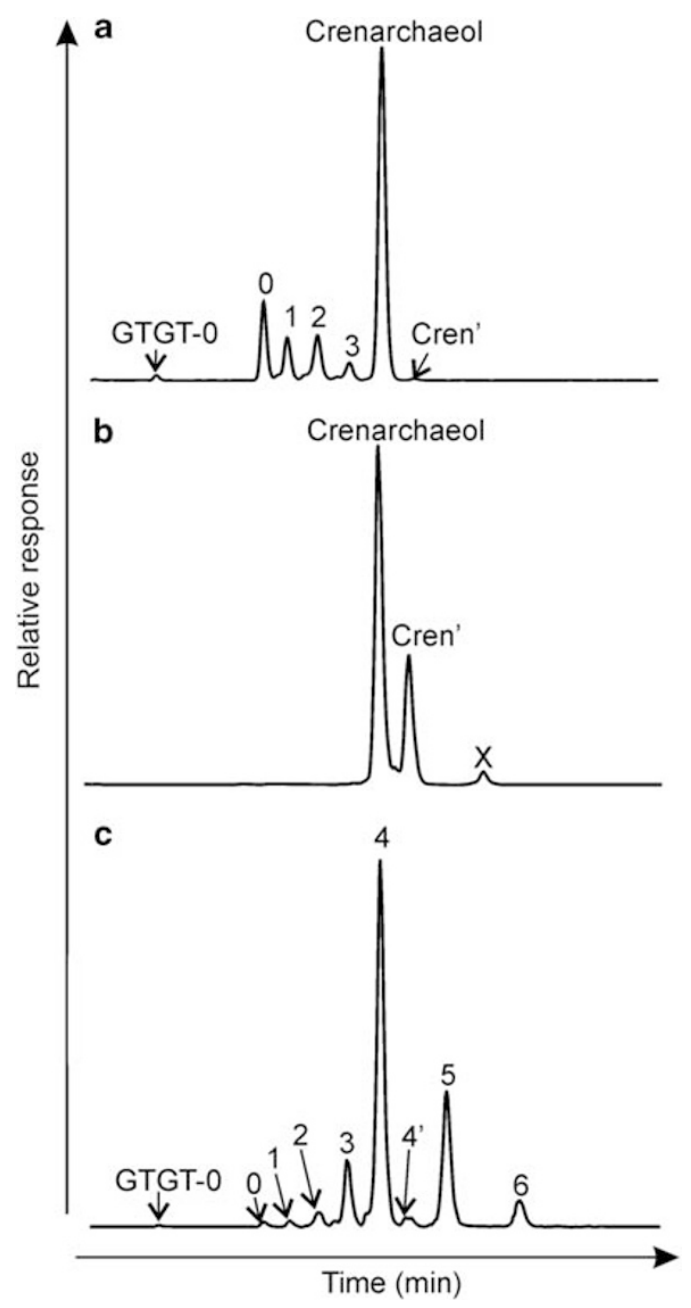

Figure 2 High-performance liquid chromatography (HPLCAPCI) base peak chromatograms showing glycerol dialkyl glycerol tetraethers (GDGTs) derived from acid-hydrolyzed biomass of (a) Nitrosopumulis maritimus SCM1 (Schouten et al., 2008), (b) 'Candidatus Nitrososphaera gargensis' grown at $46^{\circ} \mathrm{C}$ and (c) Sulfolobus solfataricus P2 strain DSM1617 (Ellen et al., 2009). Peak labels: glycerol trialkyl tetraether (GTGT)-0 is labeled as such; other peaks follow GDGT designations according to Figure 1 (e.g., '1' = GDGT-1).

pound is quite similar to that of the biphytane containing two cyclopentane moieties and a cyclohexane moiety present in crenarchaeol (Schouten et al., 1998), except that the fragment ions 165 and 263 are now 2 Da lower. These fragments would be consistent with the same biphytane carbon skeleton present in crenarchaeol, but containing an additional cyclopentane moiety at the end of the alkyl chain. Indeed, it is well-known that hyperthermophilic Crenarchaeota make cyclopentane moieties at this position of the biphytane carbon skeleton when grown at high temperatures (de Rosa and Gambacorta, 1988). Based on this, the structure of GDGT-X was tentatively identified as being nearly identical to that of crenarchaeol but with an additional cyclopentane moiety (Figure 1).

To test whether ' $\mathrm{Ca}$. N. gargensis' would adjust its GDGT composition when grown at different 
Table 1 Relative abundance of GDGTs recovered from acid-hydrolyzed biomass of the original enrichment culture material, and 'Candidatus Nitrososphaera gargensis' grown at 42,46 and $50{ }^{\circ} \mathrm{C}$

\begin{tabular}{|c|c|c|c|c|c|c|c|c|c|c|c|}
\hline \multirow[t]{2}{*}{ Growth temperature $\left({ }^{\circ} \mathrm{C}\right)$} & \multicolumn{9}{|c|}{ GDGT relative abundance } & \multirow[t]{2}{*}{$T E X_{86}$} & \multirow[t]{2}{*}{ TEX $X_{86}$-temp $\left({ }^{\circ} \mathrm{C}\right)$} \\
\hline & 0 & 1 & 2 & 3 & 4 & $4^{\prime}$ & cren & cren $^{\prime}$ & $X$ & & \\
\hline $46^{\mathrm{a}}$ & 0.10 & 0.12 & 0.15 & 0.32 & 2.2 & 6.2 & 65 & 21 & 4.5 & 0.994 & 45.1 \\
\hline 42 & 0.32 & 0.38 & 0.47 & 1.0 & 1.1 & 2.1 & 69 & 24 & 1.6 & 0.985 & 44.6 \\
\hline 46 & 0.12 & 0.14 & 0.17 & 0.38 & 2.0 & 8.3 & 65 & 19 & 4.2 & 0.993 & 45.1 \\
\hline 50 & 0.10 & 0.13 & 0.17 & 0.38 & 1.5 & 4.1 & 70 & 21 & 2.3 & 0.994 & 45.1 \\
\hline
\end{tabular}

Abbreviations: cren, crenarchaeol; cren', crenarchaeol regioisomer; GDGT, glycerol dialkyl glycerol tetraether; TEX ${ }_{86}$, TetraEther Index of tetraethers consisting of 86 carbon atoms.

GDGT numbers correspond to structures shown in Figure 1.

${ }^{\text {a }}$ Original enrichment culture used to innoculate media incubated at 42,46 and $50^{\circ} \mathrm{C}$ (below).
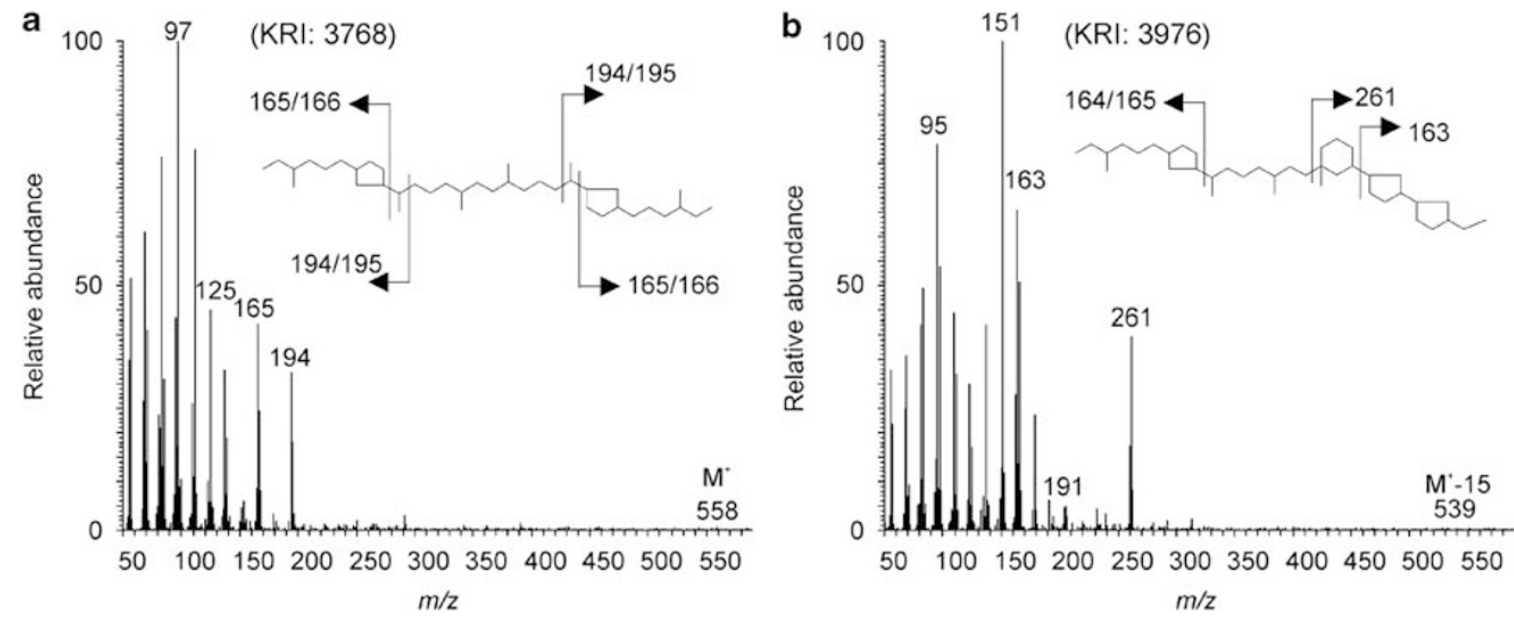

Figure 3 (a, b) Mass spectra corresponding to biphytanes released from a prepared glycerol dialkyl glycerol tetraether (GDGT) fraction enriched in GDGT-X after treatment with $\mathrm{HI} / \mathrm{LiAlH}_{4}$. Kirchman retention indices (KRI) are indicated in brackets.

temperatures, media was inoculated with the original enrichment culture and incubated at 42 , 46 and $50{ }^{\circ} \mathrm{C}$ for 3 weeks. Acid hydrolysis of biomass harvested during the end of logarithmic phase growth revealed that, at all the three temperatures crenarchaeol and its regioisomer remained the most abundant GDGTs, with significant amounts of GDGT-X. There were also notable amounts of GDGT-4 and an unknown isomer of GDGT-4 in the $46{ }^{\circ} \mathrm{C}$ culture, which were less abundant in the original enrichment culture. Furthermore, at all growth temperatures, 'Ca. N. gargensis' continued to produce only minor amounts of GDGTs $0-3$, each comprising $\leqslant 2 \%$ of total GDGTs, and barely detectable amounts of GTGT-1 and GDGT-6 (data not shown). The relative abundances of GDGTs $0-3$ were slightly higher at $42{ }^{\circ} \mathrm{C}$ than at 46 and $50{ }^{\circ} \mathrm{C}$. In contrast, the relative abundances of GDGTs 4 and X, were highest at $46^{\circ} \mathrm{C}$ (Table 1).

\section{Intact polar lipids}

High-performance liquid chromatography-electrospray ionization/mass spectrometry analysis of the Bligh and Dyer extract of 'Ca. N. gargensis' showed four peaks with single molecular ions and two major peak clusters with IPLs that were not baseline separated (Figure 4). Based on their mass spectra, resulting from in-source fragmentation, six IPLs were tentatively identified (Table 2, Figure 4).

The first peak (1) was identified as crenarchaeol with a glycosidically bound hexose headgroup (Figure 4). The dominant ions included 1454, 1471 and 1476, representing the $[\mathrm{M}+\mathrm{H}]^{+}$of the IPL, ammonium $\left(\left[\mathrm{M}+\mathrm{NH}_{4}\right]^{+}\right)$and sodium $\left([\mathrm{M}+\mathrm{Na}]^{+}\right)$ adducts, respectively. An additional dominant ion at $\mathrm{m} / \mathrm{z} 1292$ indicated that crenarchaeol or the crenarchaeol regioisomer was the core GDGT of this polar lipid.

The second peak (2) appeared to consist of a single IPL with a protonated molecule at $\mathrm{m} / \mathrm{z} 1629 \mathrm{Da}$ $\left(\left[\mathrm{M}+\mathrm{NH}_{4}\right]^{+}\right.$and $[\mathrm{M}+\mathrm{Na}]^{+}$at $\mathrm{m} / \mathrm{z} 1647$ and 1652, respectively) and fragments at $\mathrm{m} / \mathrm{z} 1292$ and 1454 corresponding to crenarchaeol and crenarchaeol with a monohexose group. This suggests that this IPL is a monohexose crenarchaeol with an additional but unknown headgroup of $176 \mathrm{Da}$; however, it was not possible to determine the structure of this additional headgroup based on MS. Similar intact polar GDGTs with a headgroup of $176 \mathrm{Da}$ have, to the 
Hexose,

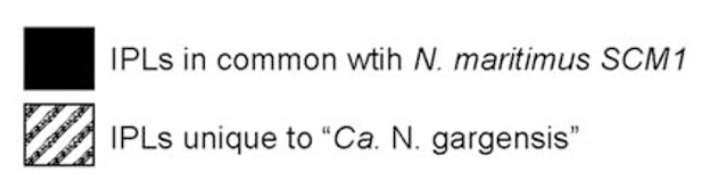
phospho-hexose

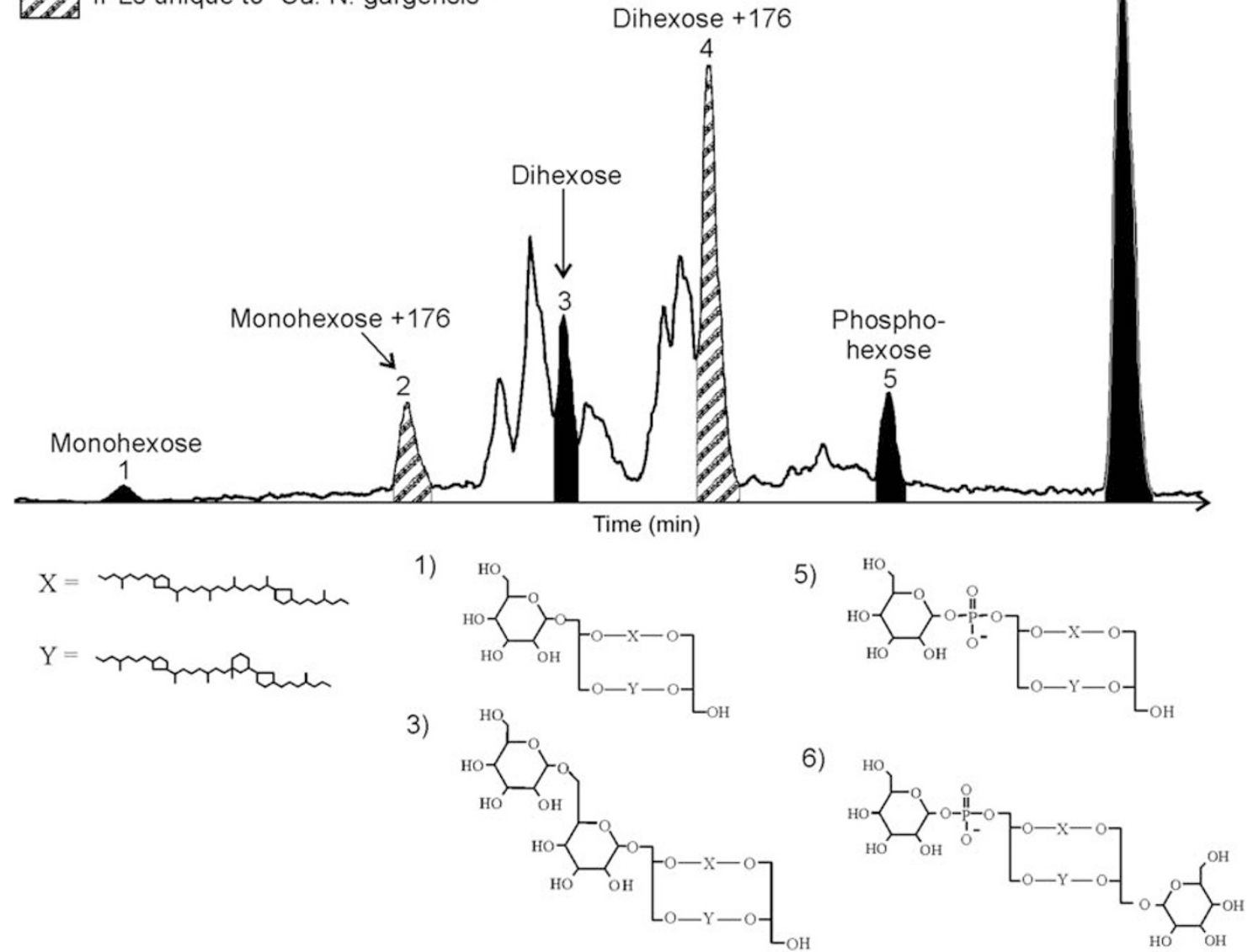

Figure 4 High-performance liquid chromatography-electrospray ionization/mass spectrometry (HPLC-ESI/MS)-base peak chromatogram of intact polar lipids (IPL) extracted from 'Candidatus Nitrososphaera gargensis'. Numbered peaks correspond to structures described in Table 2 and tentative structures drawn below the chromatogram (with the exception of IPLs eluting in peaks 2 and 4 , which were not drawn because of the unknown nature of the 176 Da moiety). Stars indicate unknown compounds with fragment ions below $\mathrm{m} / \mathrm{z}$ 1200 (i.e., not GDGT-based).

Table 2 Summary of the main ions in the mass spectra of the intact polar lipids of 'Candidatus Nitrososphaera gargensis' shown in Figure 4.

\begin{tabular}{|c|c|c|c|c|c|}
\hline Peak & Fragments & {$[\mathrm{M}+\mathrm{H}]^{+}$} & {$\left[\mathrm{M}+\mathrm{NH}_{4}\right]^{+}$} & {$[\mathrm{M}+\mathrm{Na}]^{+}$} & Headgroup \\
\hline 1 & 1292 & 1454 & 1471 & 1476 & Monohexose \\
\hline 2 & 1292,1454 & 1630 & 1647 & 1652 & Monohexose+176 \\
\hline 3 & 1292 & 1616 & 1633 & 1638 & Dihexose \\
\hline 4 & 1292,1454 & 1792 & 1809 & 1814 & Dihexose+176 \\
\hline 5 & None & 1534 & 1556 & 1578 & Phospho-hexose \\
\hline 6 & 1534 & 1696 & 1713 & 1718 & Hexose, phospho-hexose \\
\hline
\end{tabular}

best of our knowledge, not yet been reported elsewhere. The molecular weight of the headgroup is $14 \mathrm{Da}$ higher than that of a hexose moiety, suggesting that it is possibly a methylated hexose moiety. However, further identification by isolation and NMR techniques is needed to confirm this hypothesis.

Most peaks in the cluster-containing peak 3 (indicated by stars, Figure 4) contained ions with $\mathrm{m} / \mathrm{z}$ ratios below 1200 in their mass spectra, suggesting that they did not contain GDGTs as core lipids. This was not surprising as the culture was an enrichment containing multiple species of bacteria in addition to ' $\mathrm{Ca}$. N. gargensis'. The GDGT-based IPL eluting in Peak 3 itself gave a mass spectrum identical to that described previously for diglycosidic GDGTs (Schouten et al, 2008), with $[\mathrm{M}+\mathrm{H}]^{+}$, $\left[\mathrm{M}+\mathrm{NH}_{4}\right]^{+}$and $[\mathrm{M}+\mathrm{Na}]^{+}$ions corresponding to 
$\mathrm{m} / \mathrm{z}$ values of 1616,1633 and 1638 , respectively. Most peaks in the next eluting cluster (Figure 4) consisted mainly of unknown compounds, again unrelated to GDGTs as they had fragment ions all below 1200. The IPL eluting in peak 4, with an $[\mathrm{M}+\mathrm{H}]^{+}$at $\mathrm{m} / \mathrm{z}$ 1792, had an MS suggestive of diglycosidic crenarchaeol with an additional unknown headgroup of 176 Daltons. Likely, this unknown headgroup is the same as that found for the IPL represented by peak 2 .

The MS of the IPL eluting in peak 5 (Figure 4) is in agreement with that of phospho-hexose crenarchaeol based on the $\mathrm{m} / \mathrm{z}$ values of 1534,1556 and 1578, which corresponded to the $[\mathrm{M}+\mathrm{H}]^{+}$, $\left[\mathrm{M}+\mathrm{NH}_{4}\right]^{+}$and $[\mathrm{M}+\mathrm{Na}]^{+}$ions, respectively (Table 2). This compound has been reported in N. maritimus SCM1 (Schouten et al., 2008). Finally, the IPL in the last eluting peak (6) (Figure 4) had a mass spectrum suggestive of crenarchaeol with a glycosidically bound hexose headgroup and a phospho-hexose headgroup with $\mathrm{m} / \mathrm{z}$ values of 1696, 1713 and 1718 corresponding to the $[\mathrm{M}+\mathrm{H}]^{+}$, $\left[\mathrm{M}+\mathrm{NH}_{4}\right]^{+}$and $[\mathrm{M}+\mathrm{Na}]^{+}$ions, respectively (Figure 3, Table 2). This IPL has also been described previously for N. maritimus SCM1 (Schouten et al., 2008).

\section{Discussion}

Phylogenetic occurrence of crenarchaeol

Our results show that 'Candidatus N. gargensis', a moderately thermophilic, ammonia-oxidizing Group I.1b Crenarchaeon, synthesizes crenarchaeol as its main core membrane GDGT. This expands the phylogenetic distribution of crenarchaeol synthesis to include, in addition to the marine Group I.1a Crenarchaeota (Sinninghe Damsté et al., 2002; Schouten et al., 2008) and the ThAOA/HWCG III clade (de la Torre et al., 2008), the soil Group I.1b Crenarchaeota, which all belong to the monophyletic lineage of AOA recently described by Prosser and Nicol (2008) (cf. Figure 5). In addition, our findings confirm previous circumstantial evidence for crenarchaeol synthesis by Group I.1b Crenarchaeota based on the ubiquitous presence of crenarchaeol in soils (Weijers et al., 2006), and the significant correlation linking ammonia-oxidizing soil Archaea to crenarchaeol synthesis (Leininger et al., 2006). Our results signify that all cultivated representatives of Group I Crenarchaeota to date synthesize crenarchaeol, thus providing support for the suggested specificity of crenarchaeol to Archaea involved in ammonia oxidation (de la Torre et al., 2008). Crenarchaeol has also been detected at sites of archaeal ammonia oxidation in the marine water column of the coastal North Sea (Wuchter et al., 2006), the Black Sea (Coolen et al., 2007), Icelandic hot springs (Reigstad et al., 2008), Nevada and California hot springs (Pearson et al., 2004; Zhang et al., 2006; Pitcher et al., 2009) and agricultural

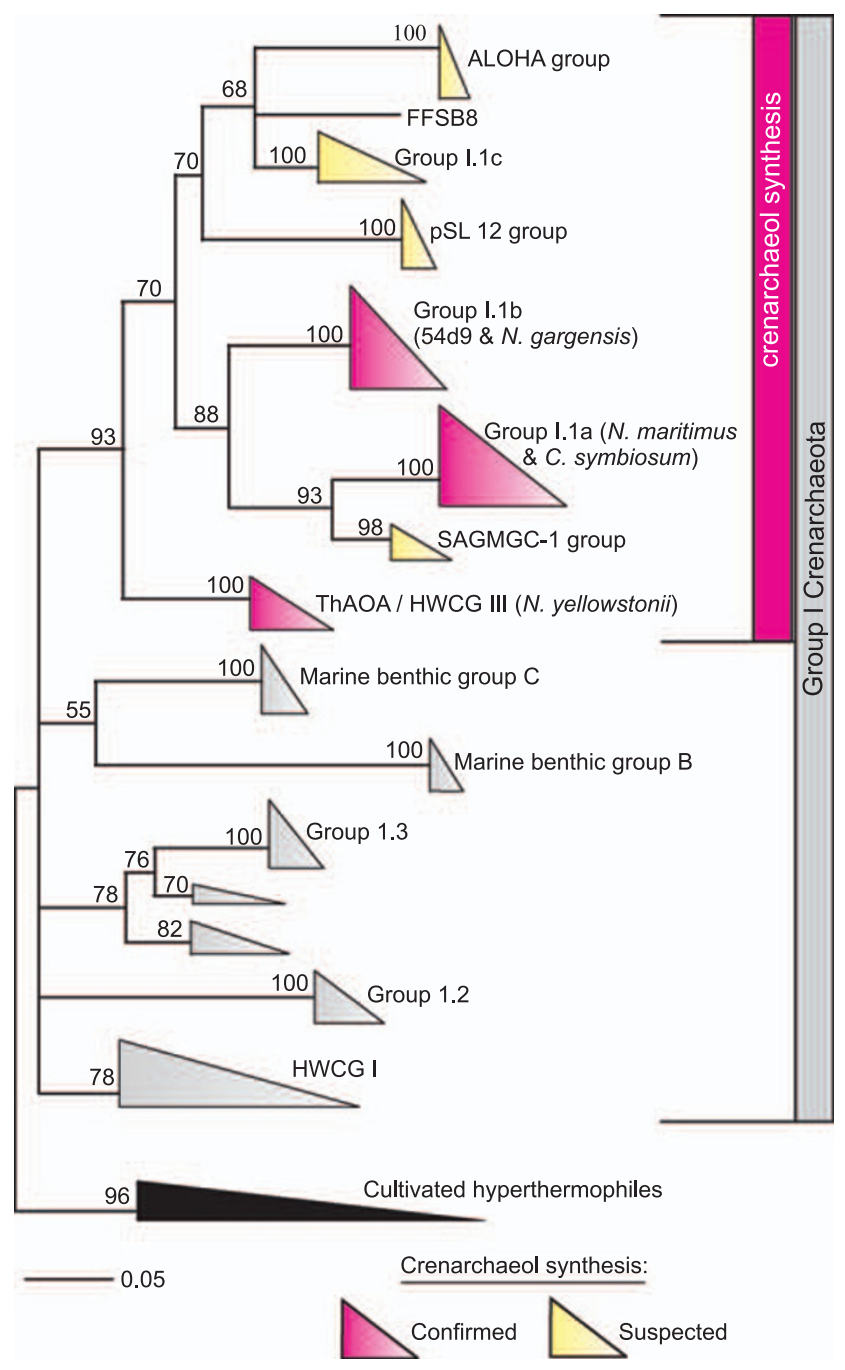

Figure 5 16S rRNA gene-based phylogeny of the Crenarchaeota redrawn from Prosser and Nicol highlighting confirmed and suspected crenarchaeol synthesizers within the 'Group I' Crenarchaeota based on the potential widespread distribution of archaeal ammonia-oxidization within this monophyletic clade and its hypothesized link to crenarchaeol synthesis.

soils (Leininger et al., 2006). Although Wuchter et al. (2006) and Leininger et al. (2006) found a strong correlation between crenarchaeol abundance and amoA copy numbers, but because of a lack of cultured representatives from Group I Crenarchaeota falling outside the recognized AOA, it yet cannot be unambiguously concluded that crenarchaeol synthesis is actually restricted to AOA.

Our results differ from those of $N$. maritimus and other AOA enrichment cultures in that the GDGT composition of 'Candidatus N. gargensis' is dominated by crenarchaeol and the crenarchaeol regioisomer (cf. Figures 2a and b). All previously analyzed AOA contained substantial amounts of other GDGTs in addition to crenarchaeol, most notably GDGT-0 in N. maritimus SCM1 (Schouten et al., 2008) and C. symbiosium (Sinninghe Damsté et al., 2002), and large amounts of glycerol trialkyl glycerol tetraethers 
synthesized by 'Ca. N. yellowstonii' (de la Torre et al., 2008). These large differences in tetraether distribution between the different organisms may be due to the different optimal growth temperatures of individual isolates/enrichment cultures, which range from $28{ }^{\circ} \mathrm{C}$ for $N$. maritimus SCM1 to $72{ }^{\circ} \mathrm{C}$ for ' $C a$. N. yellowstonii'. Indeed, cultivation of 'Ca. N. gargensis' at temperatures lower than its optimal growth temperature resulted in a slight increase in GDGT-0. Alternatively, these differences in composition may reflect genetic differences affecting membrane lipid biosynthesis between the phylogenetic clusters I.1a, I.1b and ThAOA/HWCG III. The later hypothesis implies that differences in the Crenarchaeota community composition between environmental samples may have a notable effect on the composition of environmental GDGT assemblages.

\section{Specific GDGTs for phylogenetic clusters in Group I Crenarchaeota}

The core lipids of ' $\mathrm{Ca}$. N. gargensis' contain a unique GDGT-X (Figures 1 and 2). The addition of a cyclopentane moiety is homologous to thermophilic temperature adaptations observed in other cultivated hyperthermophiles (for example, Sulfolobus), which increase the number of cyclopentane rings in their GDGTs as temperature increases. Indeed, this GDGT is not found in the mesophilic $N$. maritimus $S C M 1$, but it was also not reported to be present in the thermophilic ' $C a$. N. yellowstonii' by de la Torre et al. (2008). The relative amount of GDGT-X also did not increase when 'Ca. N. gargensis' was grown at higher temperatures. Thus, GDGT-X may be unique to (thermophilic) Group I.1b Crenarchaeota rather than an adaptation to elevated growth temperature.

' $C a$. N. gargensis' also synthesizes two IPL headgroups containing moieties corresponding to $176 \mathrm{Da}$ (Figure 4, peaks 2 and 4). To the best of our knowledge, such a moiety has not been reported as yet for cultures or in natural environments. Schouten et al. (2008) reported IPLs with an unknown headgroup of $180 \mathrm{Da}$ in N. maritimus SCM1, which is not present in ' $C a$. N. gargensis'. On the other hand, 'Ca. N. gargensis' also synthesizes some IPLs with headgroups identical to those synthesized by N. maritimus SCM1 (Schouten et al., 2008); IPLs with a monohexose, dihexose and hexosephosphohexose moieties (Figure 4) are common to both species, thereby indicating that these IPLs may become useful biomarkers for broad AOA screens. Direct detection of some crenarchaeal IPLs (that is, containing crenarchaeol) has been achieved in deep sea sediments using HPLC-ESI/MS (Sturt et al., 2004; Biddle et al., 2006). They found IPLs containing crenarchaeol with hexose and dihexose moieties, but not with a phospo-hexose moiety that is present in both $N$. maritimus SCM1 and ' $C a$. $\mathrm{N}$. gargensis'. It is interesting to note that they also found GDGTs with an unknown headgroup of
$180 \mathrm{Da}$, similar to that synthesized by $N$. maritimus SCM1. This might indicate a specific contribution of Group I.1a Crenarchaeota in deep-sea sediments, although they did not recover any Group I.1a Crenarchaeal 16S rRNA gene sequences from their clone libraries. An alternative explanation is that archaeal members derived from, for example, Marine Benthic Group B, which were well-represented in those recovered sequences, synthesize similar IPL headgroups and possibly crenarchaeol. Again, cultivated representatives of sedimentary Archaea are needed to confirm this.

\section{Distribution and occurrence of the crenarchaeol regioisomer}

The crenarchaeol regioisomer has, until now, been reported in very low (that is, $<5 \%$ of total GDGTs) amounts in cultured/enriched Group I Crenarchaeota representatives. Neither $N$. maritimus nor C. symbiosum synthesize substantial amounts of the regioisomer in culture (Schouten et al., 2008; Sinninghe Damsté et al., 2002), and only trace amounts were observed in ' $\mathrm{Ca}$. Nitrosocaldus yellowstonii' when grown at $72{ }^{\circ} \mathrm{C}$ (de la Torre et al., 2008). Similarly, only small amounts of the regioisomer were found in marine Group I.1a archaeal enrichments obtained from the North Sea (Wuchter et al., 2004) and the Indian Ocean (Schouten et al., 2007a) when cultivated over a range of temperatures (5-35 ${ }^{\circ} \mathrm{C}$ and $25-40{ }^{\circ} \mathrm{C}$, respectively). Trace amounts of crenarchaeol regioisomer detected in these cultures and enrichments show that these Group I Crenarchaeota are indeed capable of synthesizing the crenarchaeol regioisomer; however, only appear to do so to a small degree.

Despite its limited production in cultured Crenarchaeota until now, the crenarchaeol regioisomer is abundant in some natural environments, particularly in tropical marine waters and sediments as well as in lake sediments, though its abundance rarely exceeds ca. $15 \%$ of the corresponding crenarchaeol concentration (Schouten et al., 2002; Wuchter et al., 2005; Kim et al., 2008). In some tropical soils, however, the relative abundance of the crenarchaeol isomer is much higher and approaches ca. $40 \%$ of the local crenarchaeol concentration (Weijers et al., 2006). Members of the soil Group I.1b crenarchaeota with a GDGT composition similar to that of ' $\mathrm{Ca}$. N. gargensis' are likely responsible for this unusual environmental GDGT pattern. A potential contribution of Group I.1b Crenarchaeota to the increased crenarchaeol regioisomer abundances in tropical marine waters and sediments appears less parsimonious, as sequences affiliated with Group I.1b are not often reported in open marine environments. For example, Herfort et al. (2007) and Coolen et al. (2007) only found $16 \mathrm{~S}$ rRNA gene sequences related to marine Group I Crenarchaeota in the North Sea and the Black Sea water columns, respectively. It should, 
however, be noted that Group I.1b sequences have indeed been recovered from some marine sediments (for example, Park et al., 2008; Sahan and Muyzer, 2008) and corals (Beman et al., 2007). Thus, three plausible explanations exist for the high regioisomer abundance in tropical marine waters: (i) culture conditions used to enrich or cultivate marine Group I.1a Crenarchaeota till now have simply not been effective at stimulating production of the crenarchaeol regioisomer, (ii) previously overlooked Group I.1b AOA are responsible for the regioisomer production in tropical marine waters or (iii) large differences in crenarchaeol regioisomer production exist among individual Group I.1a species. The latter two hypotheses are supported by Shah et al. (2008), who present evidence supporting alternative biological or geographical origins of crenarchaeol regioisomer, which was isolated from a mixed sedimentary GDGT assemblage.

Our results also have implications for $\mathrm{TEX}_{86}$ paleothermometry, as paleoreconstructions of sea surface temperatures using $\mathrm{TEX}_{86}$ rely on the inclusion of the crenarchaeol regioisomer in the calculated $\mathrm{TEX}_{86}$ ratio. If regioisomer synthesis is not only controlled by temperature, but also by the occurrence of specific phylogenetic clusters of Crenarchaeota producing enhanced amounts of the regioisomer, then this may complicate the use of the $\mathrm{TEX}_{86}$. Such a scenario may explain part of the scatter observed in the $\mathrm{TEX}_{86}$-temperature calibration (Kim et al., 2008). At this point, however, it is impossible to evaluate which potential shifts in TEX $_{86}$-temperature estimates will be caused by shifts in crenarchaeal populations in the natural environment, as such community shifts are potentially influenced by a wide variety of factors including optimal growth temperatures, substrate availability, presence of competitors and predators, and species biogeography.

Our results with ' $\mathrm{Ca}$. N. gargensis' may be used to test the $\mathrm{TEX}_{86}$ at high temperatures, although we note that ' $\mathrm{Ca}$. N. gargensis' is a moderately thermophilic organism isolated from a non-marine environment. A $\mathrm{TEX}_{86}$ value of 1 would (linearly) extrapolate to a temperature of $45.4{ }^{\circ} \mathrm{C}$ using the Kim et al. (2008) calibration. This occurs when the crenarchaeol regioisomer is highly dominating over GDGTs 1-3, such as what is observed for ' $C a$. $\mathrm{N}$. gargensis'; the $\mathrm{TEX}_{86}$-derived temperature calculated from our biomass grown at $46^{\circ} \mathrm{C}$ was $45.1^{\circ} \mathrm{C}$ (cf. Table 1). There was no notable difference in the relative GDGT abundances when ' $\mathrm{Ca}$. N. gargensis' was grown at 46 or $50{ }^{\circ} \mathrm{C}$, but at $42{ }^{\circ} \mathrm{C}$ the increase in the relative abundance of GDGTs $1-3$ resulted in a slightly lower, but analytically robust, TEX $_{86}$ (Table 1). The $\mathrm{TEX}_{86}$ empirical relationship predicts a more pronounced increase in GDGTs 1-3 than we observed-that is, shifting from 46 to $42{ }^{\circ} \mathrm{C}$ should correspond to a $\mathrm{TEX}_{86}$ decrease of 0.050 (that is, from 0.99 to 0.94 ). The measured $\mathrm{TEX}_{86}$ decrease of only 0.008 signifies that factors in addition to temperature influence the membrane GDGT distribution at high (and likely low) temperatures, rendering the GDGT-temperature relationship nonlinear in these regions. Nevertheless, our results indicate that temperature does indeed exert some influence over the relative abundance of these GDGTs among individual species within the Group I.1b, similar to the phenomena observed by incubation experiments with Group I.1a Crenarchaeota (Wuchter et al., 2004; Schouten et al., 2007a).

Ultimately, the confirmation of crenarchaeol synthesis within the soil Group I.1b Crenarchaeota further supports the hypothesis that crenarchaeol is synthesized by all Archaea carrying out ammonia oxidation. However, as no cultivated representatives outside the recognized AOA lineages of the Group I Crenarchaeota are available at this moment, it cannot yet be evaluated how widespread crenarchaeol synthesis is among this group. ' $C a$. N. gargensis' is the first AOA for which the production of large amounts of the crenarchaeol regioisomer has been demonstrated, suggesting that Group I.1b Crenarchaeota are a likely source of the documented elevated regioisomer abundances in some natural environments. Furthermore, the unique lipids (a new GDGT and IPL with new headgroups) synthesized by ' $\mathrm{Ca}$. $\mathrm{N}$. gargensis' may prove useful in future studies as biomarkers for Group I.1b Crenarchaeota or a subclade of this group. Screening more crenarchaeal enrichment cultures, as they become available for their IPLs will determine if indeed this is the case. In contrast, environmental screening for IPLs common to $N$. maritimus and ' $\mathrm{Ca}$. N. gargensis' (for example, crenarchaeol with a hexose and phosphohexose headgroup) may prove useful for the general detection of AOA.

\section{Acknowledgements}

Funding for this research was provided by the Dutch Darwin Institute for Biogeology, the NIOZ Royal Netherlands Institute for Sea Research and DFG German Research Foundation (project SP 667/7-370-1). Elena Lebedeva, University of Moscow, is thanked for providing the original material from which ' $\mathrm{Ca}$. N. gargensis' analyzed in this paper was enriched. Three anonymous reviewers are thanked for providing constructive comments, which led to the improvement of this manuscript.

\section{References}

Beman JM, Francis CA. (2006). Diversity of ammoniaoxidizing archaea and bacteria in the sediments of a hypernutrified subtropical estuary: Bahia del Tobari, Mexico. Appl Environ Microbiol 72: 7767-7777.

Beman JM, Popp BN, Francis CA. (2008). Molecular and biogeochemical evidence for ammonia oxidation by marine Crenarchaeota in the Gulf of California. ISME J 2: 429-441.

Beman JM, Roberts KJ, Wegley L, Rohwer F, Francis CA. (2007). Distribution and diversity of archaeal ammonia monooxygenase genes associated with corals. Appl Environ Microbiol 73: 5642-5647. 
Biddle JF, Lipp JS, Lever MA, Lloyd KG, Sorensen KB, Anderson $\mathrm{R}$ et al. (2006). Heterotrophic archaea dominate sedimentary subsurface ecosystems off Peru. Proc Natl Acad Sci USA 103: 3846-3851.

Bligh EG, Dyer WJ. (1959). A rapid method of total lipid extraction and purification. Can J Biochem Physiol 37: 911-917.

Coolen MJL, Abbas B, van Bleijswijk J, Hopmans EC, Kuypers MMM, Wakeham SG et al. (2007). Putative ammonia-oxidizing Crenarchaeota in suboxic waters of the Black Sea: a basin-wide ecological study using $16 \mathrm{~S}$ ribosomal and functional genes and membrane lipids. Environ Microbiol 9: 1001-1016.

de la Torre JR, Walker CB, Ingalls AE, Konneke M, Stahl DA. (2008). Cultivation of a thermophilic ammonia oxidizing archaeon synthesizing crenarchaeol. Environ Microbiol 10: 810-818.

de Rosa M, Gambacorta A. (1988). The lipids of archaebacteria. Prog Lipid Res 27: 153-175.

Ehrich S, Behrens D, Lebedeva E, Ludwig W, Bock E. (1995). A new obligately chemolithoautotrophic, nitrite-oxidizing bacterium, nitrospira-moscoviensis sp-nov and its phylogenetic relationship. Arch Microbiol 164: 16-23.

Ellen AF, Albers SV, Huibers W, Pitcher A, Hobel CFV, Schwarz H et al. (2009). Proteomic analysis of secreted membrane vesicles of archaeal Sulfolobus species reveals the presence of endosome sorting complex components. Extremophiles 13: 67-79.

Francis CA, Beman JM, Kuypers MMM. (2007). New processes and players in the nitrogen cycle: the microbial ecology of anaerobic and archaeal ammonia oxidation. ISME J 1: 19-27.

Francis CA, Roberts KJ, Beman JM, Santoro AE, Oakley BB. (2005). Ubiquity and diversity of ammonia-oxidizing archaea in water columns and sediments of the ocean. Proc Natl Acad Sci USA 102: 14683-14688.

Hatzenpichler R, Lebecleva EV, Spieck E, Stoecker K, Richter A, Daims $\mathrm{H}$ et al. (2008). A moderately thermophilic ammonia-oxidizing crenarchaeote from a hot spring. Proc Natl Acad Sci USA 105: 2134-2139.

Herfort L, Schouten S, Abbas B, Veldhuis MJW, Coolen MJL, Wuchter C et al. (2007). Variations in spatial and temporal distribution of archaea in the North Sea in relation to environmental variables. FEMS Microbiol Ecol 62: 242-257.

Hoefs MJL, Schouten S, deLeeuw JW, King LL, Wakeham SG, Damste JSS. (1997). Ether lipids of planktonic archaea in the marine water column. Appl Environ Microbiol 63: 3090-3095.

Hopmans EC, Schouten S, Pancost RD, van der Meer MTJ, Sinninghe Damsté JS. (2000). Analysis of intact tetraether lipids in archaeal cell material and sediments by high performance liquid chromatography/atmospheric pressure chemical ionization mass spectrometry. Rapid Commun Mass Spectrom 14: 585-589.

Kim J-H, Schouten S, Hopmans EC, Donner B, Sinninghe Damsté JS. (2008). Global sediment core-top calibration of the $\mathrm{TEX}_{86}$ paleothermometer in the ocean. Geochim Cosmochim Acta 72: 1154-1173.

Könneke ME, de la Torre JR, Walker CB, Waterbury JB, Stahl DA. (2005). Isolation of an autotrophic ammonia-oxidizing marine archaeon. Nature 437: 543-546.

Krümmel A, Harms H. (1982). Effect of organic-matter on growth and cell yield of ammonia-oxidizing bacteria. Arch Microbiol 133: 50-54.
Leininger S, Urich T, Schloter M, Schwark L, Qi J, Nicol GW et al. (2006). Archaea predominate among ammonia-oxidizing prokaryotes in soils. Nature 442: 806-809.

Macalady JL, Vestling MM, Baumler D, Boekelheide N, Kaspar CW, Banfield JF. (2004). Tetraether-linked membrane monolayers in Ferroplasma spp: a key to survival in acid. Extremophiles 8: 411-419.

Martens-Habbena W, Berube PM, Urakawa H, de la Torre JR, Stahl DA. (2009). Ammonia oxidation kinetics determine niche separation of nitrifying archaea and bacteria. Nature 461: 976-979.

Mincer TJ, Church MJ, Taylor LT, Preston C, Kar DM, Delong EF. (2007). Quantitative distribution of presumptive archaeal and bacterial nitrifiers in Monterey Bay and the North Pacific Subtropical Gyre. Environ Microbiol 9: 1162-1175.

Park SJ, Park BJ, Rhee SK. (2008). Comparative analysis of archaeal 16S rRNA and amoA genes to estimate the abundance and diversity of ammonia-oxidizing archaea in marine sediments. Extremophiles 12: 605-615.

Pearson A, Huang Z, Ingalls AE, Romanek CS, Wiegel J, Freeman $\mathrm{KH}$ et al. (2004). Nonmarine crenarchaeol in Nevada hot springs. Appl Environ Microbiol 70: 5229-5237.

Pitcher A, Schouten S, Damste JSS. (2009). In Situ production of crenarchaeol in two California hot springs. Appl Environ Microbiol 75: 4443-4451.

Prosser JI, Nicol GW. (2008). Relative contributions of archaea and bacteria to aerobic ammonia oxidation in the environment. Environ Microbiol 10: 2931-2941.

Reigstad LJ, Richter A, Daims H, Urich T, Schwark L, Schleper C. (2008). Nitrification in terrestrial hot springs of Iceland and Kamchatka. FEMS Microbiol Ecol 64: 167-174.

Sahan E, Muyzer G. (2008). Diversity and spatio-temporal distribution of ammonia-oxidizing archaea and bacteria in sediments of the Westerschelde estuary. FEMS Microbiol Ecol 64: 175-186.

Schouten S, Forster A, Panoto FE, Sinninghe Damsté JS. (2007a). Towards calibration of the $\mathrm{TEX}_{86}$ palaeothermometer for tropical sea surface temperatures in ancient greenhouse worlds. Org Geochem 38: 1537-1546.

Schouten S, Hoefs MJL, Koopmans MP, Bosch HJ, Sinninghe Damsté JS. (1998). Structural characterization, occurrence and fate of archaeal ether-bound acyclic and cyclic biphytanes and corresponding diols in sediments. Org Geochem 29: 1305-1319.

Schouten S, Hopmans EC, Baas M, Boumann H, Standfest S, Könneke $M$ et al. (2008). Intact membrane lipids of 'Candidatus Nitrosopumilus maritimus,' a cultivated representative of the cosmopolitan mesophilic group I crenarchaeota. Appl Environ Microbiol 74: 2433-2440.

Schouten S, Hopmans EC, Schefuß E, Sinninghe Damsté JS. (2002). Distributional variations in marine crenarchaeotal membrane lipids: a new tool for reconstructing ancient sea water temperatures? Earth Planet Sci Lett 204: 265-274.

Schouten S, Huguet C, Hopmans EC, Kienhuis MVM, Sinninghe Damsté JS. (2007b). Analytical methodology for TEX86 paleothermometry by high-performance liquid chromatography/atmospheric pressure chemical ionization-mass spectrometry. Anal Chem 79: 2940-2944. 
Schouten S, van der Meer MTJ, Hopmans E, Rijpstra WI, Reysenbach A-L, Ward DM et al. (2007c). Archaeal and bacterial glycerol dialkyl glycerol tetraether lipids in hot springs of Yellowstone National Park. Appl Environ Microbiol 73: 6181-6191.

Shah SR, Mollenhauer G, Ohkouchi N, Eglinton TI, Pearson A. (2008). Origins of archaeal tetraether lipids in sediments: insights from radiocarbon analysis. Geochim Cosmochim Acta 72: 4577-4594.

Sinninghe Damsté JS, Schouten S, Hopmans EC, van Duin ACT, Geenevasen JAJ. (2002). Crenarchaeol: the characteristic core glycerol dibiphytanyl glycerol tetraether membrane lipid of cosmopolitan pelagic crenarchaeota. J Lipid Res 43: 1641-1651.

Smittenberg RH, Hopmans EC, Schouten S, Sinninghe Damsté JS. (2002). Rapid isolation of biomarkers for compound specific radiocarbon dating using highperformance liquid chromatography and flow injection analysis-atmospheric pressure chemical ionisation mass spectrometry. J Chromatogr A 978: 129-140.

Steger D, Ettinger-Epstein P, Whalan S, Hentschel U, de Nys R, Wagner M et al. (2008). Diversity and mode of transmission of ammonia-oxidizing archaea in marine sponges. Environ Microbiol 10: 1087-1094.

Sturt HF, Summons RE, Smith K, Elvert M, Hinrichs K-U. (2004). Intact polar membrane lipids in prokaryotes and sediments deciphered by high-performance liquid chromatography/electrospray ionization multistage mass spectrometry-new biomarkers for biogeochem- istry and microbial ecology. Rapid Commun Mass Spectrom 18: 617-628.

Weijers JWH, Schouten S, Spaargaren OC, Sinninghe Damsté JS. (2006). Occurrence and distribution of tetraether membrane lipids in soils: Implications for the use of the $\mathrm{TEX}_{86}$ proxy and the BIT index. Org Geochem 37: 1680-1693.

Wuchter C, Abbas B, Coolen MJL, Herfort L, van Bleijswijk J, Timmers $\mathrm{P}$ et al. (2006). Archaeal nitrification in the ocean. Proc Natl Acad Sci USA 103: 12317-12322.

Wuchter C, Schouten S, Coolen MJL, Sinninghe Damsté JS. (2004). Temperature-dependent variation in the distribution of tetraether membrane lipids of marine Crenarchaeota: implications for $\mathrm{TEX}_{86}$ paleothermometry. Paleoceanography 19: PA4028.

Wuchter C, Schouten S, Wakeham SG, Sinninghe Damsté JS. (2005). Temporal and spatial variation in tetraether membrane lipids of marine Crenarchaeota in particulate organic matter: implications for $\mathrm{TEX}_{86}$ paleothermometry. Paleoceanography 20: PA 3013.

Zhang CL, Pearson A, Li YL, Mills G, Wiegel J. (2006). Thermophilic temperature optimum for crenarchaeol synthesis and its implication for archaeal evolution. Appl Environ Microbiol 72: 4419-4422.

Zhang CL, Ye Q, Huang ZY, Li WJ, Chen JQ, Song ZQ et al. (2008). Global occurrence of archaeal amoA genes in terrestrial hot springs. Appl Environ Microbiol 74: 6417-6426. 